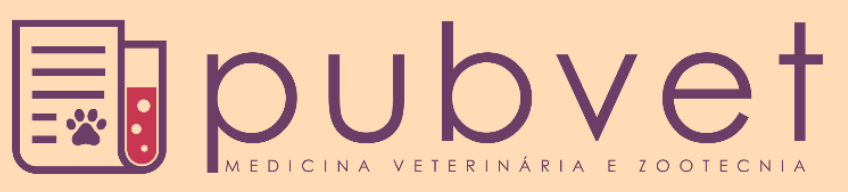

https://doi.org/10.31533/pubvet.v14n8a637.1-18

\title{
Osteossíntese de ossos longos em aves: Revisão
}

\author{
Hugo Augusto Mendonça Canelas ${ }^{1 *} \bullet$, Alessandra Souza Negrão ${ }^{2} \bullet$, Amanda Melo Hamoy ${ }^{1}{ }^{\bullet}$, \\ Paulo Sérgio Campos $\operatorname{Cruz}^{10}$, Reinaldo Matangrano Neto ${ }^{\circ}$, Erica Flávia Silva Azevedo ${ }^{2}{ }^{\circ}$, \\ Leony Soares Marinho ${ }^{\circ}{ }^{\circ}$, Hamilton da Silva Pinto Junior ${ }^{30}$
}

${ }^{1}$ Discente da universidade federal rural da amazonia (UFRA) Departamento de Medicina Veterinária. Belém-Pa Brasil.

${ }^{2}$ Médico veterinário(a) autônomo(a). Belém, PA, Brasil.

${ }^{3}$ Docente da Universidade Federal Rural da Amazônia (UFRA). Departamento de Medicina Veterinária. Belém-PA, Brasil.

*Autor para a correspondência, E-mail: canelashugo098@gmail.com

Resumo: Os ossos são constituintes fulcrais do sistema locomotor, além da função de sustentação e proteção de tecidos e órgãos adjacentes. Os traumas são as maiores enfermidades que ocorrem as aves, representando cerca de $20 \%$ de toda casuística de animais atendidos, onde a fratura é mais notada, sendo as de ossos longos as mais predominantes, principalmente umerais e tibiotarsais. É de notória importância avaliar o animal quanto aos seguintes sinais clínicos: dor local, deformidade angular do membro, mobilidade óssea anormal, edema local, impotência funcional do membro, claudicação e crepitação local. Em aves, os principais tratamentos recomendados para afecções ortopédicas são utilização de bandagens, pinos intramedulares, fixadores externos e repouso em gaiola. Por conta do tamanho diminuto e da constituição fina e leve dos ossos, a utilização de placas ósseas é rara, sendo usadas apenas em casos específicos de fraturas. Afecções traumáticas em aves, com destaque para fraturas, tem se tornado cada vez mais comuns na rotina do médico veterinário e necessitam de intervenção terapêutica. Todavia, poucos são os profissionais que se arriscam a realizar tais procedimentos, pela existência de características físicas e fisiológicas distintas dessa classe, carecendo de grande conhecimento anatômico e princípios básicos de cirurgia ortopédica geral.

Palavras chave: aves, cirurgia veterinária, ortopedia

\section{Osteosynthesis of long bones in birds: Review}

Abstract. Bones are key components of the locomotor system, in addition to the function of supporting and protecting adjacent tissues and organs. Trauma is the biggest disease that occurs in birds, representing about $20 \%$ of all cases of animals treated, where the fracture is more noted, with long bones being the most prevalent, mainly humeral and tibiotarsal. It is notorious to evaluate the animal for the following clinical signs: local pain, angular deformity of the limb, abnormal bone mobility, local edema, functional impotence of the limb, lameness and local crackling. In birds, the main treatments recommended for orthopedic conditions are the use of bandages, intramedullary pins, external fixators and rest in a cage. Due to the small size and the thin and light constitution of the bones, the use of bone plates is rare, being used only in specific cases of fractures. Traumatic disorders in birds, especially fractures, have become increasingly common in the veterinarian's routine and require therapeutic intervention. However, few professionals risk taking such procedures, due to the existence of different physical and physiological characteristics of this class, lacking great anatomical knowledge and basic principles of general orthopedic surgery.

Keywords: birds, veterinary surgery, ortopedics 


\section{Osteosintesis de huesos largos en aves: Revisión}

Resumen: Los huesos son componentes clave del sistema locomotor, además de la función de soporte y protección de los tejidos y órganos adyacentes. Los traumas son frecuentes en las aves, representando aproximadamente el $20 \%$ de todos los casos de animales tratados, donde la fractura es mayoritariamente notada, siendo en los huesos largos los más prevalentes, principalmente humeral y tibiotarsal. Es notorio evaluar al animal por los siguientes signos clínicos: dolor local, deformidad angular de la extremidad, movilidad ósea anormal, edema local, impotencia funcional de la extremidad, cojera y crepitación local. En las aves, los principales tratamientos recomendados para afecciones ortopédicas son el uso de vendajes, pinos intramedulares, fijadores externos y descanso en una jaula. Debido al tamaño pequeño y la constitución delgada y ligera de los huesos, el uso de placas óseas es raro, y se usa solo en casos específicos de fracturas. Los trastornos traumáticos en las aves, especialmente las fracturas, se han vuelto cada vez más comunes en la rutina del veterinario y requieren intervención terapéutica. Sin embargo, pocos profesionales se arriesgan a tomar estos procedimientos, debido a la existencia de diferentes características físicas y fisiológicas de esta clase, que carecen de un gran conocimiento anatómico y principios básicos de cirugía ortopédica general.

Palabras clave: aves, cirugía Veterinaria, ortopedia

\section{Introdução}

Os ossos são constituintes do sistema locomotor, possuem função de sustentação e proteção de tecidos e órgãos (Slatter, 1998). O tecido ósseo é vivo e especializado, constituído basicamente por compostos orgânicos e inorgânicos, por exemplo, células especializadas e elementos minerais, como cálcio e fósforo. É um tecido que apresenta pouca vascularização, o que dificulta o processo cicatricial (Ferrigno et al., 2014).

Segundo Gondim et al. (2006) e Santos et al. (2008), as afecções traumáticas são as maiores enfermidades que acometem as aves, com cerca de $20 \%$ de toda casuística de animais atendidos, onde as fraturas ganham destaque, sendo as de ossos longos as mais incidentes, principalmente umerais e tibiotarsais (Bush, 1974).

Ferrigno et al. (2014) relataram que quando se suspeita de fratura, o ideal é avaliar o animal quanto aos sinais clínicos: dor local, deformidade angular do membro, mobilidade óssea anormal, edema local, impotência funcional do membro, claudicação e crepitação local. Recomenda-se o uso de raio-x como ferramenta para fechar o diagnóstico da fratura e, assim, avaliar e definir a melhor abordagem. Se a técnica escolhida envolve a utilização de dispositivos intramedulares, além da opção de utilização de fixadores externos (Denny \& Butterworth, 2000).

Em aves, os tratamentos propostos para afecções ortopédicas são utilização de bandagens, pinos intramedulares, fixadores externos e repouso em gaiola. Por conta do tamanho diminuto e da constituição fina e leve dos ossos, a utilização de placas ósseas é rara, sendo usadas apenas em casos específicos de fraturas (Ferrigno et al., 2014).

Assim, o objetivo deste trabalho foi identificar os fatores que levam a fraturas em aves, bem como os ossos mais acometidos e as principais técnicas utilizadas, mediante revisão de literatura, visando o crescente interesse pela clínica de animais selvagens compreendendo literatura acerca do assunto nos últimos anos.

\section{Osteologia de aves}

Existem aproximadamente 8900 espécies de aves no mundo, não sendo possível considerar todos os aspectos da anatomia e fisiologia da classe. Portanto, serão consideradas apenas as variações relevantes ao presente trabalho.

O sistema esquelético das aves constitui-se por um sistema eficiente, forte, leve e aerodinâmico, possuindo adaptações específicas (como penas, músculos, sistemas circulatório e respiratório) que permitem o voo (Macwhirter, 2009). São encontrados dois tipos principais de ossos em aves, ossos pneumáticos e ossos medulares 
Os ossos pneumáticos, cujo interior se conecta aos sacos aéreos, proporciona leveza à estrutura óssea. Estão presentes no crânio, vértebras, pelve, esterno, costelas, úmero e fêmur, porém a pneumatização dos ossos varia entre as espécies. Os ossos medulares se caracterizam pela presença de espirais interconectantes que crescem a partir da superfície endosteal do osso cortical e enchem a cavidade medular em resposta a presença de estrógenos, fornecendo reserva de cálcio para a composição da casca dos ovos (Macwhirter, 2009).

Muitos ossos em aves são fundidos, com o intuito, mais uma vez, diminuir o peso, aumentar a força da estrutura e melhorar a aerodinâmica. Começando pelo crânio, em todas as aves este é uniforme, com a presença do bico córneo, que apresenta variações consideráveis entre as espécies. A articulação do crânio ao atlas se dá por um único côndilo occipital (Coles, 2007).

A coluna vertebral é dividida em vértebras cervicais, vértebras torácicas (fundidas), sinsacro (fusão das vértebras lombares, sacrais e caudais), secção caudal livre e caudal fusionada (pigóstilo) (Dyce et al., 2004). As vértebras cervicais caudais e as vértebras torácicas estão aderidas às costelas. As costelas cervicais são curtas e fundidas as vértebras, enquanto as costelas torácicas possuem articulação dorsal com as vértebras e ventral com o esterno (osso da quilha). Os processos uncinados ancoram os bordos caudais de uma costela até a borda cranial da subsequente, conferindo força a caixa torácica, porém dificultando o acesso cirúrgico desta (Macwhirter, 2009).

O cinturão torácico é composto pela escápula (longa e estreita), clavícula (fundidas medialmente, formando um $\mathrm{V}$ ou "wishbone") e o osso coracóide, atuando como suporte para as asas. A quilha presente no esterno é uma estrutura bem desenvolvida em aves voadoras e reduzida ou ausente em ratites (aves sem capacidade de voo). No geral, a estrutura das asas é semelhante em todas as espécies de aves, com variações nos comprimentos relativos dos ossos individuais. O úmero é curto, robusto e pneumático, contendo uma extensão do saco aéreo clavicular na extremidade proximal. A ulna é mais longa que o rádio. O carpometacarpo é formado pela fusão de dois ossos proximais do carpo, ossos distais do carpo e três ossos do metacarpo. Na extremidade distal do membro, há presença de 3 dígitos, sendo eles: alula (ou asa bastarda), dígito maior (maior dentre os dígitos, com duas falanges) e dígito menor (Macwhirter, 2009).

A pelve é composta pelos ossos íleo, ísquio e púbis parcialmente fundidos um ao outro e ao sinsacro, porém a púbis não se funde ventralmente, permitindo a passagem de ovos. Assim como nas asas, as pernas são semelhantes em todas as espécies, com a maioria das mudanças evolutivas ocorridas nos pés. O fêmur de assemelha ao de mamíferos e possui movimento basicamente cranial e caudal, com rotação lateral limitada. O tibiotarso é formado pela fusão da tíbia com os ossos tarsais proximais, enquanto o tarsometatarso é formado pela fusão dos ossos tarsais distais e os três principais ossos do metatarso (Coles, 2007; Macwhirter, 2009). O jarrete é formada entre o tibiotarso e o tarsometatarso, que se prolonga em direção ao solo, originando 4 dedos, que diferem entre as espécies (Dyce et al., 2004).

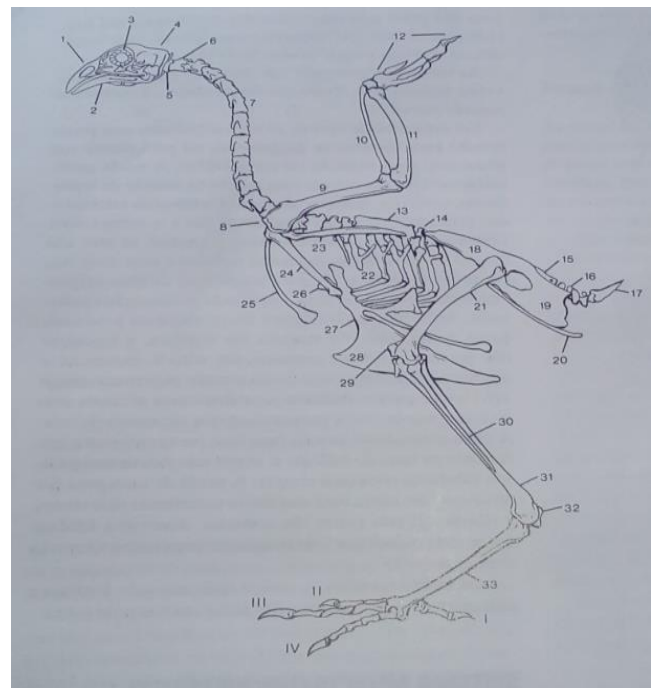

Figura 1. Esqueleto de galinha (Gallus gallus domesticus). Fonte: Dyce et al. (2004). 


\section{Estrutura do osso}

O osso é um tecido conjuntivo duro e especializado, que sustenta o corpo, dá movimento e proteção, e serve ainda como reserva de minerais. É formado por dois componentes básicos: matéria orgânica e matéria inorgânica, sendo a parte orgânica constituída por células especializadas (osteoblastos, osteócitos e osteoclastos) e fibras colágenas, formando a base para deposição da matéria inorgânica e elementos minerais, principalmente cálcio e fósforo, proporcionando ao osso sua particular dureza pela formação dos cristais de hidroxiapatita. Externamente, é envolvido por um tecido chamado periósteo, que possui em seu interior vasos sanguíneos, uma camada de tecido conjuntivo denso fibroso (cápsula) e células osteogênicas. Internamente, encontra-se a cavidade medular, revestida pelo endósteo e preenchida por células-tronco sanguíneas (Junqueira \& Carneiro, 2013; Samuelson, 2011).

De acordo com Samuelson (2011), os ossos são classificados com base em seu desenvolvimento, configuração e organização. Tendo em vista o desenvolvimento, podem ser classificados em imaturos e maduros. O imaturo está presente nos fetos, nos centros primários e secundários de ossificação e, após o nascimento, na primária esponjosa. Possui natureza esponjosa e é convertido em forma madura no processo de desenvolvimento do corpo. O osso maduro caracteriza-se por ser mais compacto devido sua organização ordenada, dada a disposição helicoidal de fibras colágenas.

Pela configuração, temos osso esponjoso e compacto. O esponjoso é menos denso, com lâminas ósseas dispostas em sentidos variados, irregulares, criando espaços entre si (trabéculas), que são ocupados por medula óssea, responsável pela produção de células sanguíneas. O compacto é mais denso, composto por lâminas ósseas paralelas e extremamente próximas, conferindo resistência ao osso (Samuelson, 2011).

Organizacionalmente, Samuelson (2011) dividiu em osso lamelar e osteonal. O osso lamelar consiste em camadas ósseas depositadas a partir do periósteo e do endósteo, externa e internamente. O osso osteonal consiste em camadas ósseas dispostas de forma concêntrica, formando o sistema harversiano, dentro do qual encontra-se o canal de Harvers, que contém vasos sanguíneos, nervos vasomotores e células osteoprogenitoras. Perpendicular a estes, estão os canais de Volkmann, que possuem estrutura semelhante e, juntos, formam uma rede de perfusão e aporte de nutrientes para o osso (Ferrigno et al., 2014). Segundo Dunning et al. (2005) diversos estudos microscópicos nos ossos corticais de aves, observaram a presença de poucos sistemas de Harvers.

Quanto à origem histológica, podemos encontrar dois tipos: ossos planos, com origem na ossificação intramembranosa e ossos longos, com origem na ossificação endocondral (Dunning et al., 2005; Junqueira \& Carneiro, 2013; Samuelson, 2011).

A ossificação intramembranosa tem origem em células mesenquimatosas, apinhadas e hiperplásicas, formando condensações mesenquimais, enquanto outras células se diferenciam em osteoblastos, dispostos em fileiras, que começam a sintetizar e secretar substância osteóide de maneira unidirecional, que posteriormente se mineraliza. À medida que o osteóide é depositado, os osteoblastos ficam presos em lacunas na matriz, mas ainda mantém contato célula a célula por extensões citoplasmáticas, originando os primeiros osteócitos. As células do osteoprogenitor se dividem e se multiplicam, produzindo mais osteoblastos, que continuam a estabelecer o novo osso. As ilhas de ossos em formação são chamadas espículas, que se fundem em trabéculas. A princípio, o osso derivado de ossificação intramembranosa parece de natureza trabecular, mas o padrão desajustado de células, fibras de colágeno e osteóides é ajustado pelos osteoclastos, permitindo deposição osteoblástica de osso trabecular e compacto (Samuelson, 2011).

$\mathrm{Na}$ ossificação endocondral, as células mesenquimatosas primitivas se diferenciam em cartilagem hialina, formando um pequeno modelo de osso. No pericôndrio, pequenos vasos sanguíneos surgem e, com isso, células condrogênicas se tornam osteogênicas. Nas porções laterais do molde, origina-se o colar ósseo subperiosteal, que realizará a ossificação intramembranosa. Após isso, tem início a ossificação endoncondral. Assim, dentro do eixo da cartilagem, há hipertrofia dos condrócitos, que calcificam a matriz extracelular adjacente, morrendo após isso e, formando lacunas vazias cercadas de matriz de cartilagem calcificada, preenchida posteriormente por precursores osteogênicos e vasos sanguíneos. Isso cria o que conhecemos por centro primário de ossificação. Simultaneamente, o pericôndrio que envolve o eixo da cartilagem desenvolve potencial osteogênico e torna-se periósteo, que 
estabelece uma fina camada de osso. Interiormente, as células mesenquimais primitivas se diferenciam em osteoblastos e células hematopoiéticas da medula óssea. Os osteoblastos alinham os andaimes de cartilagem mineralizada e começam a produzir osso trabecular. Esses processos dão origem à diáfise do osso (Dunning et al., 2005).

Nas extremidades dos moldes de cartilagem, que posteriormente se converterão em epífises, os condrócitos aumentam sua atividade de replicação, longe da diáfise em desenvolvimento. Essa área de replicação é denominada zona de replicação. Com a criação de novas células, as mais velhas são deixadas mais para a periferia, próximas a diáfise, onde amadurecem e aumentam de tamanho, formando a zona de hipertrofia. As células mais velhas ficam cada vez mais afastadas da zona proliferativa e começam a calcificar a matriz extracelular ao redor, formando a zona de calcificação provisória. Com a morte dessas células, o tecido osteogênico penetra a matriz extracelular e forma fileiras de osteoblastos que iniciam o processo de formação do osso. A zona subsequente, de formação óssea contígua, é chamada zona de ossificação. As epífises formam centros de ossificação independentes e secundários e, a união de todas as zonas presentes forma a placa epifisária (ou placa de crescimento). O crescimento de osso longo é resultado direto da proliferação contínua e rápida da cartilagem na placa epifisária, que posteriormente mineraliza e é substituída por osso (Samuelson, 2011).

De acordo com Dunning et al. (2005), a ossificação endocondral em aves é diferente da observada em mamíferos, de várias formas, porém mesmo com a nomenclatura associada à zona da placa epifisária, muda de publicação para publicação, havendo concordância quanto ao número de zonas presentes. Algumas diferenças importantes: a zona de proliferação é relativamente maior em aves; as células da zona de hipertrofia não estão dispostas em colunas ordenadas e nem são invadidas pelo canal vascular; a placa de crescimento em aves é vascularizada por dois conjuntos de vasos, da epífise e da metáfise (Macwhirter, 2009).

Embora a cicatrização óssea seja semelhante em aves e mamíferos, em aves torna-se um pouco mais complicada pela ausência de tecidos moles adjacentes, a presença de ossos pneumáticos e as intensas forças de dispersão dos músculos peitorais do voo. A taxa de cura de uma fratura depende do deslocamento dos fragmentos da fratura, da quantidade de dano ao suprimento sanguíneo, da presença de infecção e da quantidade de movimento no local da fratura (Dunning et al., 2005).

Dunning et al. (2005) consideraram essencialmente duas classes de reparação de fratura: primária (direta) e secundária (indireta). A cicatrização primária ocorre em casos onde exista baixa deformação interfragmentária, o que ocorre geralmente quando os fragmentos são reduzidos anatomicamente e estabilizados, por meio de uma placa de compressão dinâmica. Nessas circunstâncias, há formação direta de osso lamelar na linha de fratura e nenhuma evidência de formação de calo ósseo.

Este autor relatou também que dependendo da distância entre os fragmentos, existem dois métodos de cicatrização: de contato ou por lacuna. A cicatrização por contato ocorre quando há uma ruptura inferior a $0,01 \mathrm{~mm}$, com a formação do novo osso lamelar diretamente através da linha de fratura, paralelo ao eixo longo do osso. A remodelação pelo sistema de Harvers é imediata, com cones de corte osteoclásticos cruzando a linha de fratura e trazendo células osteogênicas perivasculares, que se diferenciam em osteoblastos, produzindo osteóides. Se o intervalo de fratura for superior a $0,01 \mathrm{~mm}$ e inferior a $0,5 \mathrm{~mm}$, a cicatrização óssea ainda pode ocorrer em forma de cicatrização por lacuna. Nesse caso, as células endosteais e periosteais produzem osso lamelar, que é depositado perpendicular ao eixo longo do osso. O osso lamelar é remodelado pelo sistema de Harvers para orientação longitudinal adequada.

A ossificação primária é preferível às aves; porém, difícil de alcançar. Para isso, o uso de placas é o ideal para promover a ossificação primária e aumentar a rapidez de união com o calo menor, o que permite um retorno precoce a função e maior conforto ao animal (Dunning et al., 2005). A cicatrização secundária ocorre quando há falta de fixação e compressão rígida e, em fratura complexas e cominutivas, onde a coluna óssea não pode ser reconstituída. Esse tipo de ossificação é muito observado em fraturas de baixa estabilidade de fixação óssea interna (pinos intramedulares e cerclagens), fixação óssea e coaptação externa por moldes ou talas. É também o resultado de fraturas não tratadas, que são comumente observadas em animais selvagens e aves. A característica principal da ossificação secundária é a formação do calo ósseo, que é diretamente proporcional à quantidade de movimentação presente entre os fragmentos da fratura (Dunning et al., 2005). 
Dunning et al. (2005) dividiram a cicatrização óssea secundária em três fases: fase inflamatória, fase reparadora e fase de remodelação. A fase inflamatória se inicia imediatamente após o trauma da fratura, que está quase sempre associada a uma alteração imediata e profunda no suprimento de sangue para o osso. Dependendo da energia cinética associada à fratura, o suprimento de sangue medular e periosteal podem ser servidos. Um hematoma se forma nos tecidos moles adjacentes e envolve os fragmentos da fratura. A ruptura do suprimento vascular ao osso causa necrose dos osteócitos nos ápices dos fragmentos da fratura.

Em resposta, o local se torna hipóxico e acidótico. As células inflamatórias chegam ao local e começam o processo de fagocitose. Neutrófilos são os primeiros a chegar, seguidos por macrófagos. A presença de bactérias e matéria estranha prolonga essa fase por semanas ou até meses, dependendo da gravidade. O sistema vascular responde a isquemia tecidual e a inflamação dentro de horas, aumentando o fluxo para a cavidade medular e periósteo. O novo fluxo extraósseo de sangue emerge dos tecidos moles adjacentes ao local da fratura. Esses novos vasos fornecem células osteoprogenitoras, que agirão na construção do calo ósseo. A capacidade de fornecimento de sangue para revascularizar a fratura completamente está relacionada diretamente com a forma como a movimentação é controlada no local da fratura (Dunning et al., 2005).

A fase de reparação é anunciada pela organização do hematoma e pela formação de tecido de granulação, que torna o ambiente da fratura mais amigável às células, com uma mudança gradual no $\mathrm{pH}$ em direção a neutralidade ou alcalinidade. As células mesenquimatosas invadem o local pelo periósteo, endósteo e medula óssea e começam a formação do calo ósseo fibroso, que é mecanicamente mais rígido que o hematoma ou tecido de granulação, consistindo predominantemente de fibras colágenas tipo III produzidas por fibroblastos durante a primeira semana de lesão. As células mesenquimais que são recrutadas por proteínas morfogéneticas do osso se diferenciam em condrócitos e produzem uma matriz de cartilagem. Em um processo semelhante a ossificação endocondral, o calo da cartilagem é substituído por invasão vascular, mineralização da cartilagem e formação óssea (Dunning et al., 2005).

A fase de remodelação é caracterizada pela conversão lenta do calo ósseo (constituído de osso trabecular) por osso compacto. Osteoclastos reabsorvem o osso trabecular e depositam o osso lamelar. Com o tempo, o osso compacto é restaurado completamente e a cavidade medular é reestabelecida (Dunning et al., 2005).

Segundo Ritchie et al. (1997) e Bennett \& Kuzma (1992) a cicatrização óssea em aves ocorre mais rapidamente. Coles (2007) afirmou que em 8 dias, nas aves de pequeno porte, já é possível visualizar ao raio-X sinais de cicatrização óssea. Se em condições ótimas, em 8 dias, o espaço entre os fragmentos de fratura é preenchido por tecido fibroso e, em 9 dias, osso esponjoso. Aos 22 dias já se considera a união óssea verdadeira e, remodelação completa em torno de 6 semanas (ou aproximadamente 42 dias). Essas afirmações são corroboradas pelo estudo de Bolson \& Schossler (2008) que observaram a formação de calo ósseo a palpação em 15 dias de pós-operatório, ausência de linha de fratura e início da formação do calo ósseo à radiografia e, moderada cicatrização com presença de calo ósseo à histologia. Aos 90 dias já era observada remodelação completa a radiografia e aos 120 dias, intensa cicatrização e total remodelação óssea, histologicamente.

\section{Fratura: classificação, diagnóstico e tratamento}

Uma fratura é nada menos que uma solução de continuidade do osso ou cartilagem, acompanhada de injúrias aos tecidos moles adjacentes, em graus variados, que podem comprometer o suprimento sanguíneo local (Brinker et al., 1986).

As fraturas podem ser classificadas de diversas formas. Brinker et al. (1986) classificaram em: causa, presença de ferimento externo comunicante, extensão da lesão, direção e localização da linha de fratura e, estabilidade da fratura.

Dentre as causas, podem ser citadas:

- Violência direta: mais comum, derivada de traumas diretos ao osso;

- Violência indireta: a força é transmitida ao longo do osso ou músculo adjacente até o ponto onde ocorre a fratura; 
- Enfermidades ósseas: enfermidades que enfraquecem a estrutura óssea e levam a fraturas por situações consideradas triviais;

- Stress repetido: fratura por fadiga, alta tensão em regiões específicas.

Pela presença de um ferimento externo comunicante, temos a presença de fratura fechada, onde a fratura não se comunica com o meio externo por conta da integridade da pele que recobre a lesão; e a fratura aberta, onde há comunicação com o exterior por conta do rompimento da pele, propiciando maiores chances de contaminação da ferida e complicações posteriores. Pode ser classificada de $1^{\circ}, 2^{\circ}$ e $3^{\text {o }}$ graus, de acordo com o dano e contaminação aos tecidos moles adjacentes (Figura 2).
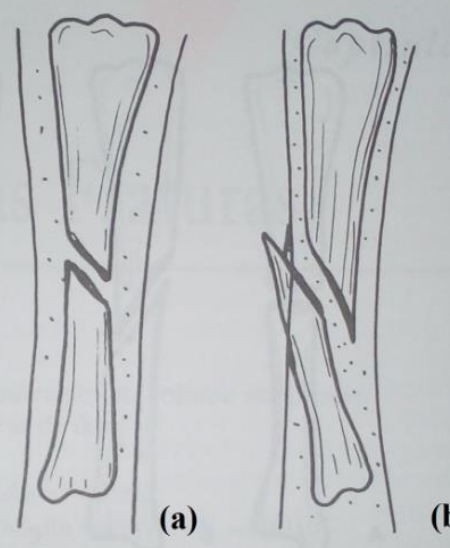

Figura 2. Classificação das fraturas quanto à presença de um ferimento externo comunicante. (A) Fratura fechada. (B) Fratura aberta. Fonte: Denny \& Butterworth (2000).

Quanto à extensão da lesão, há fratura completa, em que há total rompimento da continuidade do osso; e há fratura incompleta, onde temos fratura em galho verde, comum em animais jovens, em que um dos lados do osso fica envergado apenas e o outro ocorre a fratura de fato, e a fratura em fissura, comum a animais adultos, em que lascas penetram o córtex, mantendo a cobertura periosteal intacta (Figura 3).

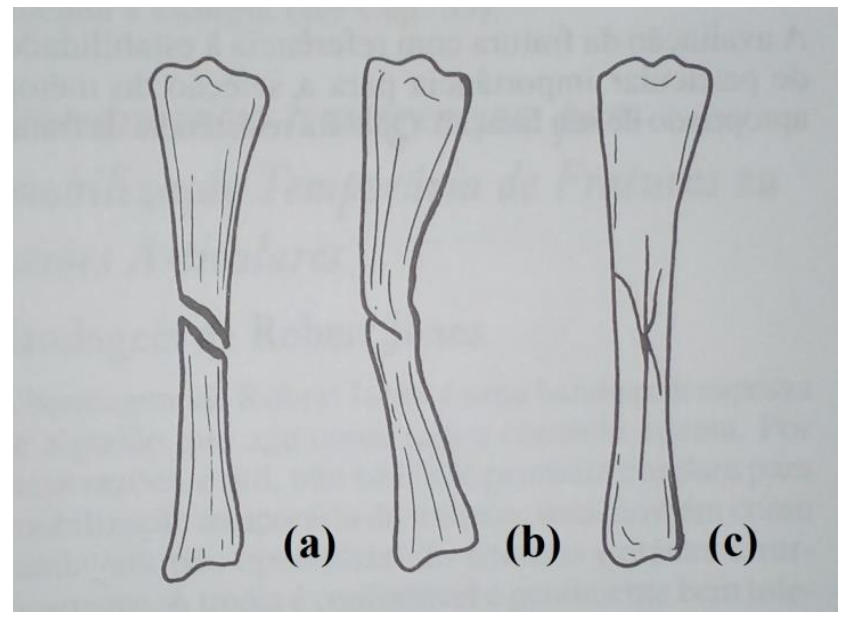

Figura 3. Classificação das fraturas de acordo com a extensão do trauma ósseo. (A) Fratura completa. (B) Fratura incompleta (fratura em galho verde). (C) Fratura incompleta (fissura). Fonte: Denny \& Butterworth (2000).

Em relação à direção e localização da linha de fratura, temos fratura transversa, fratura oblíqua, fratura em espiral, fratura cominutiva, fratura múltipla ou segmentada, fratura impactada, fratura por avulsão, fratura fiseal, fratura condílea e fratura intercondílea. A fratura transversa ocorre em ângulo reto ao eixo do osso $\left(90^{\circ}\right)$, enquanto a fratura oblíqua se dá em ângulo diagonal ao eixo do osso, com 
sobreposição óssea dos fragmentos por deslizamento. A fratura em espiral forma uma curva ao redor do osso, com deslizamento dos fragmentos ósseos por rotação. Na fratura cominutiva, há estilhaçamento dos fragmentos ósseos e comunicação das linhas de fratura, enquanto a fratura múltipla ocorre fratura em 3 ou mais segmentos, porém sem ponto comum entre as linhas de fratura. A fratura impactada ocorre por compactação dos fragmentos ósseos (um fragmento penetra o outro) (Figura 4). A fratura por avulsão resulta de uma tração vigorosa no osso, com destacamento de um fragmento ósseo, local de inserção do músculo e tendão ou ligamento. Fraturas fiseais ocorrem apenas em animais jovens, com separação dos fragmentos da fratura na linha epifisária. As fraturas condílea e intercondílea ocorrem nos côndilos, porém uma a linha de fratura passa pelo côndilo e em outra a fratura situa-se entre os côndilos.

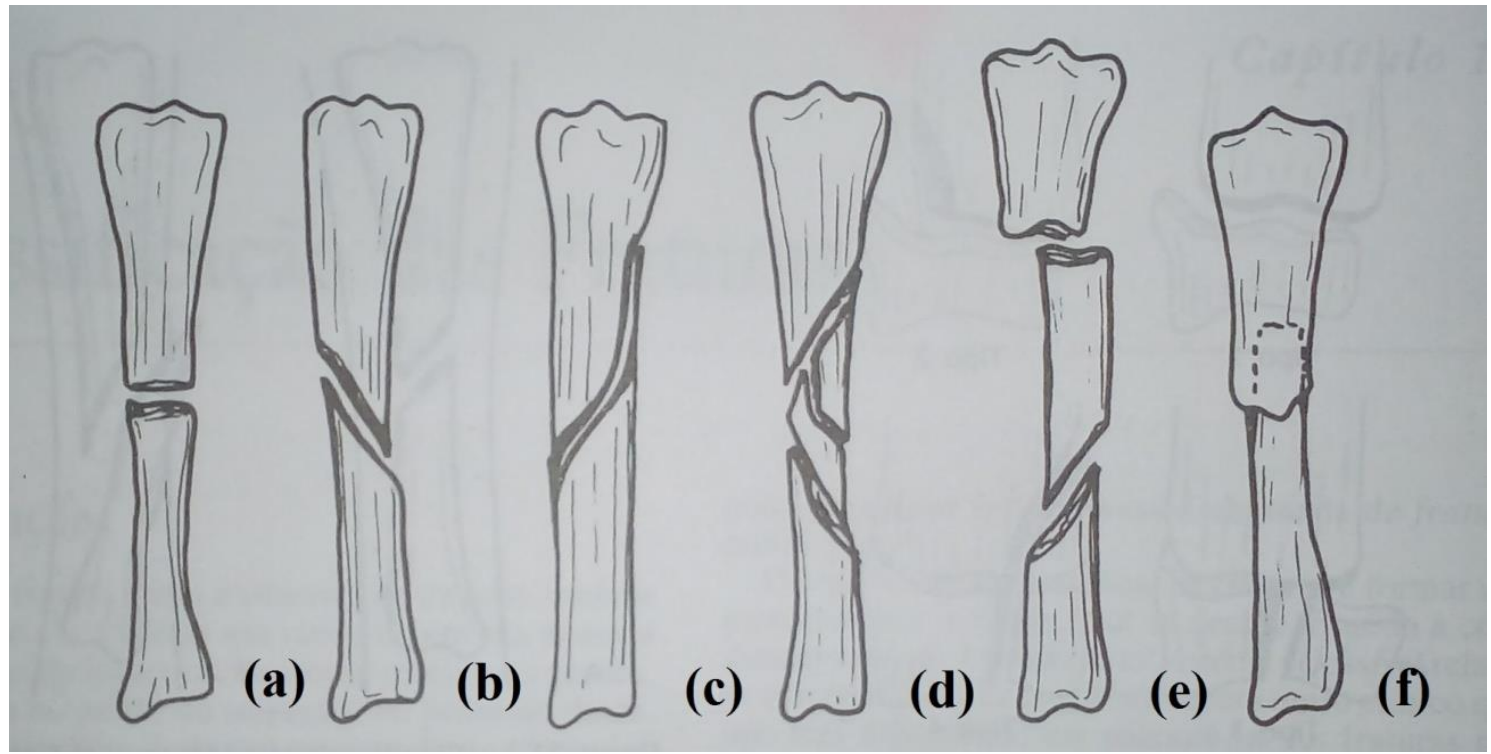

Figura 4. Classificação das fraturas conforme a direção da linha de fratura. (A) Transversa. (B) Oblíqua. (C) Espiral. (D) Cominutiva. (E) Múltipla ou segmentada. (F) Impactada. Fonte: Denny \& Butterworth (2000).

E, por fim, as fraturas classificadas quanto à estabilidade incluem fraturas estáveis e fraturas instáveis. Em fraturas estáveis, os fragmentos, ao serem reduzidos, se interligam e resistem a forças de encurtamento. $\mathrm{O}$ objetivo da fixação nesse caso é impedir da deformidade angular, utilizando pinos intramedulares, fixador externo ou placa óssea. Na fratura instável, após redução, os fragmentos não se interligam, deslizando entre si e se mantendo fora da posição anatômica ideal. O objetivo da fixação para esse caso é impedir a deformidade angular, assim como a rotação dos fragmentos, com uso de placa e parafuso ou fixador externo.

Denny \& Butterworth (2000) consideraram mais uma base para a classificação das fraturas, quanto à localização anatômica da fratura: fraturas proximais, distais e diafisárias, onde as proximais e distais podem ser subdivididas em articulares, epifisárias, fisárias ou metafisárias.

Para o diagnóstico das fraturas, o histórico do animal e os sinais clínicos apresentados são de suma importância, porém, para a determinação exata da natureza da fratura e, consequentemente, melhor avaliação do método de tratamento a ser empregado, a utilização de exames radiográficos é essencial, usualmente com avaliação de duas posições radiográficas do foco de fratura.

A princípio, deve-se zelar pela vida do animal e então pelo reparo e restauração da lesão. Para Brinker et al. (1986) o exame de um animal com uma fratura (ou suspeita) deve incluir:

- Avaliação geral do paciente

- Avaliação dos tecidos e órgãos adjacentes à fratura

- Avaliação da extensão da lesão

- Avaliação de outras partes do corpo, em busca de mais lesões ou fraturas

- Avaliação precisa da fratura

Quanto aos sinais clínicos, Ferrigno et al. (2014) listam: 
- Dor local

- Presença de deformidade angular do membro

- Mobilidade óssea anormal

- Edema local

- Perda da função do membro acometido

- Claudicação

- Crepitação

Especificamente em aves o exame inicial em animal com problemas ortopédicos pode apresentar claudicação, queda da asa, paresia, inchaço ou ferida aberta, bastante comum principalmente em fraturas de úmero e fêmur, pela pouca presença de musculatura adjacente. Bolson \& Schossler (2008) incluíram ainda falha na habilidade de voo, desnível entre as asas e extremidades distais das penas da asa comprometida, encontrando-se esta muitas vezes suja de fezes ou desgastada pela abrasão com o solo (Figura 5). Já o exame físico, onde as asas e pernas são examinadas, deve começar pelo aspecto proximal, progredindo distalmente, avaliando os ossos para a existência de fratura, desvios, inchaços e as articulações quanto à amplitude de movimento. Grifols (2008 apud Souza et al. 2010), afirmou que a avaliação de fratura em aves inicia-se com a palpação do pescoço, caixa torácica, clavícula e coracóide, tocando cuidadosamente costelas e escápula, assim como também os ossos da asa, pernas e pés, avaliando angulação e mobilidade anormais e crepitação óssea.

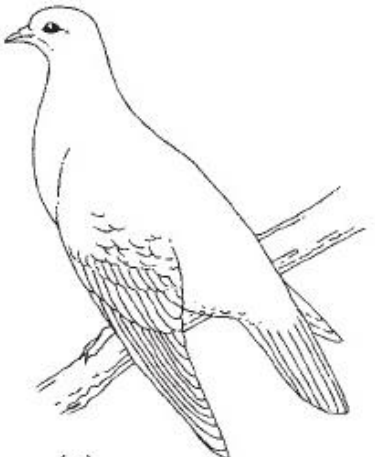

(a)

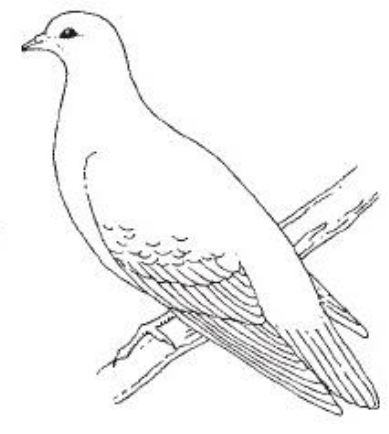

(b)

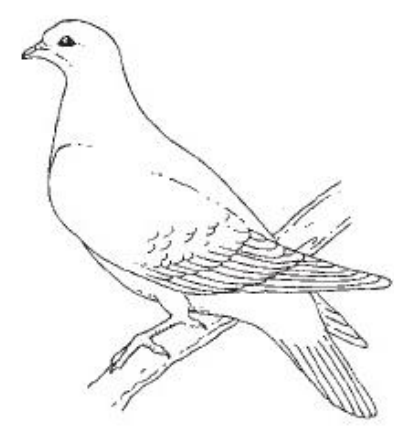

(c)

Figura 5. Aspecto da asa com fratura em diferentes segmentos. (A) Fratura entre dígitos e rádio-ulna. (B) Fratura da articulação úmero-rádio-ulnar ou de úmero. (C) Fratura de coracóide ou ombro. Fonte: $\underline{\text { Coles (2007). }}$

A determinação da existência de uma fratura e o tipo de fratura são cruciais à determinação do método a ser utilizado, visando o sucesso do tratamento.

Segundo Fossum (2014) na cirurgia ortopédica geral, os objetivos do tratamento de uma fratura devem ter o intuito de promover a cicatrização, restaurar a função do osso e dos tecidos moles adjacentes, e obter uma aparência cosmética aceitável. O tratamento pode ser feito por métodos conservadores, com a imobilização do membro utilizando-se talas e pensos, ou por métodos cirúrgicos, com utilização de pinos intramedulares, placas e parafusos ósseos ou fixadores externos (Ferrigno et al., 2014). Ritchie et al. (1997) consideraram como vantagens dos métodos cirúrgicos a redução do trauma aos tecidos moles adjacentes, melhor visualização do foco de fratura e eliminação de tecidos contaminados ou até necrosados que possam estar presentes.

Westfall \& Egger (1979) relataram a possibilidade do uso de polimetilmetacrilato (PMMA) no interior do interstício ósseo, por dois métodos. No primeiro, são feitos furos proximais e distais ao foco de fratura, que é reduzida e então inserido o PMMA em forma pastosa, posteriormente solidificando e funcionando como um pino intramedular mais leve. O segundo método associa o PMMA a fios de cerclagem completos, nas torções dos fios proximais e distais, atuando como placa de neutralização. Podem ser usados tanto em fraturas de membros torácicos e pélvicos. Para Ritchie et al. (1997) o uso de fixadores externos é bem tolerado pelas aves e representa um método seguro, barato, leve e de fácil remoção, promovendo imobilização rígida e preservando a articulação e estruturas perivasculares, neutralizando forças de rotação, arqueamento e cisalhamento. Brinker et al. (1986) afirmaram que colocação dos pinos em ângulo 
reto ao eixo do osso aumenta frequência de afrouxamentos dos pinos, considerando, então, como forma mais segura, a inserção dos pinos em ângulo aproximado de $70^{\circ}$, diminuindo as chances de complicações. Por proporcionar bom alinhamento anatômico e imobilização adequada, resulta em rápida cicatrização óssea e retorno precoce do membro, com mínima formação de calo ósseo (Bush, 1974). Já os pinos intramedulares devem ocupar 25 a 75\% do canal medular, para promover boa fixação e não interferir no suprimento sanguíneo endosteal, que pode levar a necrose ou fraturas iatrogênicas (Ritchie et al., 1997). Dentre as fraturas que podem ocorrer nos diversos ossos, daremos destaque para tratamento em úmero, rádio-ulna, fêmur, tibiotarso e tarsometatarso, que são as que possuem mais relatos na literatura e apresentam melhores resultados a métodos cirúrgicos de fixação.

As causas mais comuns de lesões ortopédicas em aves são ocasionadas por quedas, impactos contra janelas ou ventiladores de teto, esmagamento por pisada, conflitos com cães e gatos, acidentes automobilísticos, além de colisões de alta energia com fios e impactos por projéteis (Ferrigno et al., 2014; Gouvêa et al., 2011; Helmer \& Redig, 2006).

A melhor técnica a ser empregada deve levar em consideração o tamanho, tipo e localização da fratura, grau de domesticação e tranquilidade do paciente, necessidade de retorno à função, custo e habilidade do cirurgião (Ferrigno et al., 2014; Helmer \& Redig, 2006; Ritchie et al., 1997). (Ferrigno et al., 2014) relataram que a fratura é determinada diretamente pela disposição anatômica do membro. Assim, em aves pernaltas, observa-se maior incidência de fraturas umerais no terço medial, enquanto que em rapinantes ocorre mais na porção distal. As fraturas umerais tem grande importância, pois estão entre as mais incidentes (Bush, 1974) e, por conta do grande impacto que sofrem durante o voo, fazendo necessária uma completa e perfeita coaptação dos fragmentos de fratura para recuperação do animal e retorno à função (Coles, 2007). A abordagem cirúrgica do úmero é dorsal (Coles, 2007; Ferrigno et al., 2014; Ritchie et al., 1997). Em casos de fraturas proximais do úmero (menos comuns), opta-se por utilizar pinos intramedulares associados à bandagem em 8 para aves de pequeno porte (Ferrigno et al., 2014). A colocação de pinos intramedulares é considerada o método mais simples e barato; porém este apresenta muitas desvantagens, tais como a destruição da estrutura trabecular do osso, não permite a regeneração óssea endosteal e não impede a rotação dos fragmentos ósseos (Coles, 2007).

Aves de médio e grande porte são tratadas com associação de pinos cruzados e bandas de tensão, técnica onde os pinos são introduzidos na porção proximal, cruzados, de maneira retrógrada, saindo um de cada lado da crista peitoral. Os pinos são passados pelo foco de fratura, fixando o fragmento distal. É feito um orifício próximo a inserção dos pinos, nos fragmentos proximal e distal, por onde passa um fio de cerclagem, formando um oito. As pontas dos fios são então retorcidas para comprimir o foco de fratura (Ferrigno et al., 2014). Helmer \& Redig (2006) consideraram a técnica por banda de tensão a mais eficiente, enquanto Ritchie et al. (1997) aconselharam o uso de fixadores híbridos para aves de vida livre. Apesar disso, Lima et al. (2014) optaram pela utilização da técnica de Doyle na correção de uma fratura transversa completa no terço proximal de úmero esquerdo de tucano (Ramphastos toco) (Figura 6). A técnica de Doyle consiste na colocação de dois pinos intramedulares em sentidos opostos preenchendo os fragmentos proximal e distal da fratura, ficando uma porção externa de cada pino nas extremidades epifisárias opostas. Essa porção exterior é dobrada em 2 pontos e são unidas por uma liga elástica de látex estéril, comprimindo e estabilizando a fratura (Ritchie et al., 1997). Nesse caso, foram utilizadas agulhas hipodérmicas 1,7 x 50mm como pinos intramedulares. A ave apresentou retorno à função do membro com sucesso.

Para fraturas diafisárias, as mais comuns, utiliza-se pino intramedular em aves de pequeno porte. Em aves de médio e grande porte, a utilização de fixador externo isolado ou associado a pino intramedular é o mais recomendado (Ferrigno et al., 2014). Uma modificação do uso de pinos intramedulares é a técnica de "tie in" ou fixação híbrida (Coles, 2007; Helmer \& Redig, 2006). Nessa técnica, utiliza-se um pino de menor diâmetro e mais leve, que ocupará apenas 50\% da cavidade medular. Após inserido, é curvado a $180^{\circ}$ na saída. Um ou dois pinos são adicionados, inseridos transversalmente através das extremidades do osso, com cuidado para não gerar mais fraturas. Esses pinos externos são então conectados por meio de resina apropriada ou material de reparo de casco de cavalo, colocado ao redor dos pinos, formando assim uma barreira rígida, proporcionado maior estabilidade, evitando rotação de fragmentos e sendo um dispositivo relativamente leve (Coles, 2007). 


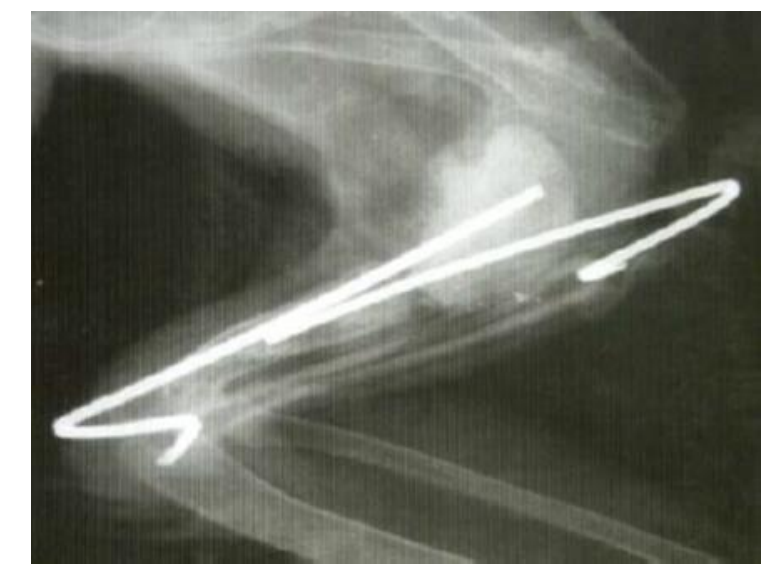

Figura 6. Radiografia evidenciando redução de fratura de úmero esquerdo de Ramphastus toco pela técnica de Doyle. Fonte: Lima et al. (2014).

Já a fixação externa é muito utilizada em aves de grande porte, com bastante sucesso. Os pinos são introduzidos através da pele, atravessando o córtex de um lado a outro do osso, num ângulo de $30-45^{\circ}$, onde 2 são introduzidos na metade proximal e 2 na metade distal do osso, fixados a uma haste paralela. Essa técnica é conhecida como método de meio pino. A técnica de pino completo é obtida quando os pinos inseridos no osso são empurrados perpendicularmente ao eixo longitudinal do osso, fixados a uma barra do outro lado do osso. As desvantagens são a utilização de muitos pinos inseridos perpendicularmente, que pode ocasionar mais fraturas no momento da inserção e o peso desse dispositivo (Coles, 2007). Mesmo assim, estudos de Westfall \& Egger (1979) corroboraram essa indicação, pela boa tolerância do animal. Leotte et al. (2004) empregaram fixador externo tipo I para osteossíntese de fratura diafisária completa transversa em pombos domésticos (Columbia livia) com pinos inseridos a $70^{\circ}$ em relação ao eixo do osso, fixados com barra de acrílico autopolimerizável e mostrou-se eficiente, com recuperação da habilidade de voo aos 28 dias pós-operatórios.

Para aves de porte menor, Coles (2007) relatou a adaptação do método de pino completo, utilizando fios de Kirschner ancorados a um pedaço de plástico preenchido com resina apropriada ou metilmetacrilato, ajustando e segurando os pinos. Westfall \& Egger (1979) consideraram que fios de Kirschner e agulhas hipodérmicas podem ser utilizados como pinos intramedulares em aves de pequeno porte, com o cuidado de não fragmentar o osso durante a técnica.

Alievi et al. (2008) testaram a eficácia de métodos utilizando pinos de Kirschner e pinos de Schauz, associados ou não a PMMA em pombos domésticos (Columbia livia). Dentre os grupos observados, o que obteve melhores resultados foi a associação de pino de Schauz e PMMA, onde o tempo de consolidação foi menor, não houve migração dos pinos, refraturas, impactação e deslocamento dos fragmentos, além de proporcionar possibilidade de voo.

Estudo de Cunha et al. (2004) em pombo doméstico (Columbia livia), em fratura de diáfise umeral, utilizaram êmbolo de seringa de $1 \mathrm{~mL}$ intraósseo associado a fios de cerclagem, em "U" (Figura 7). Os animais apresentaram perfeito alinhamento e cicatrização aos 21 dias pós-operatórios e no teste de voo, todos foram considerados satisfatórios.

Fraturas distais de úmero não são raras e o mais recomendado é o uso de fixador dinâmico transarticular. Fixa-se o aparelho ao úmero com a $1^{\mathrm{a}}$ barra no fragmento distal e a $2^{\mathrm{a}}$ barra na ulna, deixando a articulação principal do aparelho repousando sobre a articulação úmero-rádio-ulnar e a secundária a ulna, fixando a curvatura do osso e promovendo melhor apoio ao foco de fratura (Ferrigno et al., 2014) (Figura 8).

Tranquilim et al. (2007) relataram utilização de haste de polímero (êmbolo de seringa de $1 \mathrm{~mL}$ ) intraósseo, com imobilização externa em fratura exposta, completa e fragmentada na porção distal do úmero, próximo a articulação úmero-rádio-ulnar em tucano de bico verde (Ramphastus dicolorus). Esse método é ideal a aves de vida livre, pois permite a permanência do dispositivo, porém, no referido estudo, o retorno ao voo não pode ser avaliado, mas acredita-se que seja improvável, pois o animal apresentou desvio de eixo ao raio $\mathrm{x}$. 


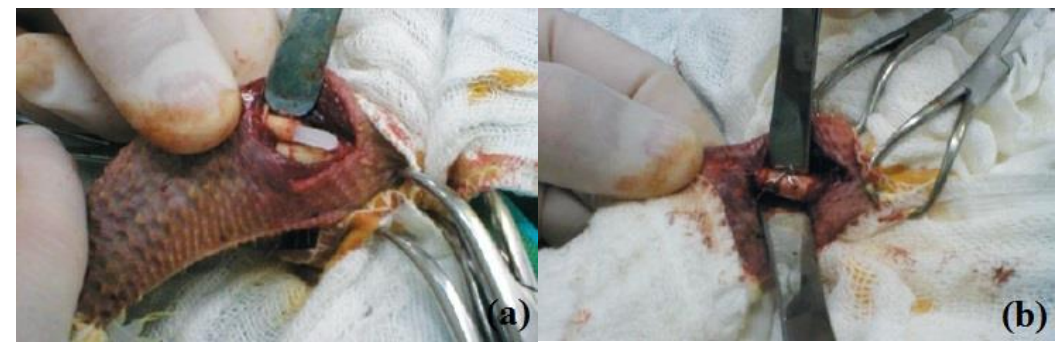

Figura 7. Osteossíntese de úmero com êmbolo de seringa em Columbia livia. (A)

Êmbolo adaptado como pino intramedular, inserido no fragmento distal. (B)

Coaptação da fratura e cerclagem em "U”. Fonte: Cunha et al. (2004).

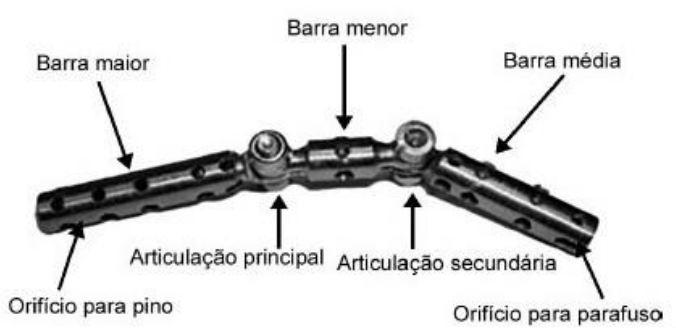

(a)

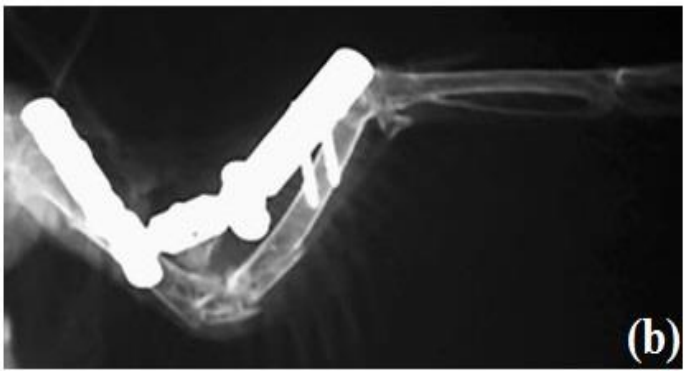

Figura 8. Fixador dinâmico transarticular. (a) Ilustração de fixador dinâmico transarticular. (b) Radiografia de fratura umeral distal em Columbia livia tratado com fixador externo transarticular. Fonte: Cubas et al. (2014).

Rocha (2011) utilizaram pino intramedular associado aos fios de cerclagem em fratura oblíqua distal de úmero esquerdo de papagaio verdadeiro (Amazona aestiva). Aos 60 dias pós-operatórios, não era possível observar a linha de fratura a radiografia e o animal apresentava estabilidade clínica do membro fraturado, porém não houve avaliação da capacidade de voo (Figura 9).

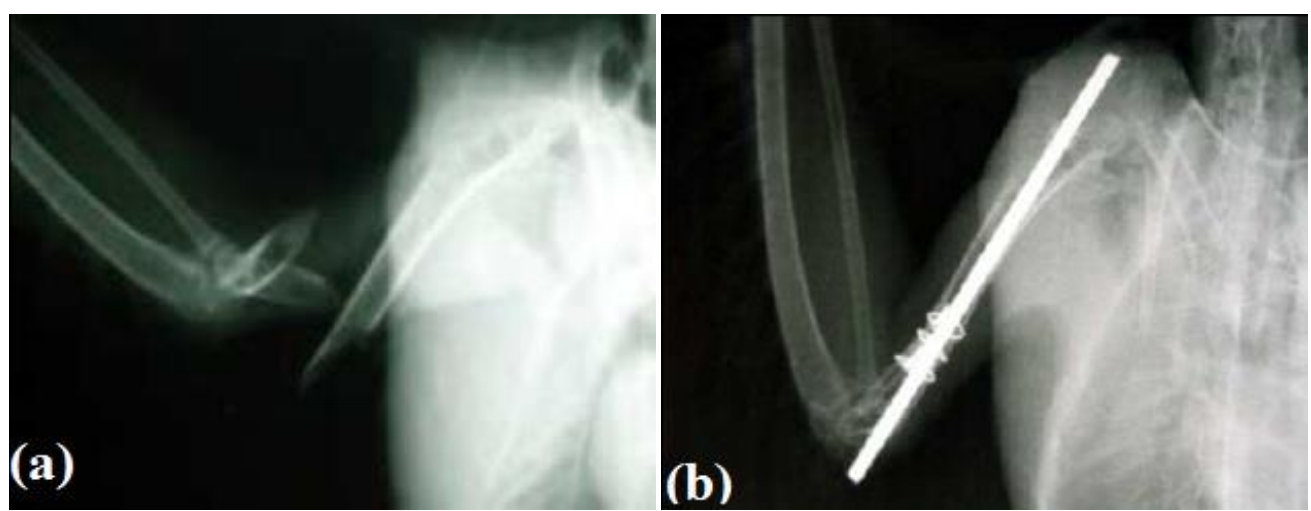

Figura 9. Imagens radiográficas de úmero esquerdo de Amazona aestiva. (A) Radiografia de fratura oblíqua distal de úmero esquerdo e fragmento condilar fraturado longitudinalmente. (B) Radiografia 60 dias pós-operatórios, demonstrando ausência de linha de fratura, com pino intramedular associado a fios de cerclagem. Fonte: Rocha (2011).

Poucos relatos são encontrados na literatura sobre o uso de enxertos e xenoenxertos ósseos em aves, devido complicações impostas a este método, como a presença de pouco osso esponjoso para colheita e a grande rejeição destes (Helmer \& Redig, 2006). Bolson \& Schossler (2008) consideraram o uso de enxerto homólogo de tibiotarso de animais sadios, preservados em glicerina a $98 \%$, para fraturas umerais de pombos domésticos (Columbia livia). Após a inserção do pino no interior do osso, um fio sintético de poliglactina 910 foi passado em hemicerclagem em ponto de Wolff, apertando e comprimindo o implante. A cicatrização do animal foi satisfatória, sem rejeição e os animais submetidos a testes de voo foram considerados normais, tornando esta uma opção bastante viável.

Wander et al. (2000 apud Bolson \& Schossler 2008) utilizaram xenoenxerto ósseo cortical, preservado por congelamento, para promover osteossíntese umeral em pombos, porém houve quebra dos enxertos. Enquanto que estudos de Gaiga \& Schossler (2003) mostraram que, utilizando 
xenoenxerto ósseo de tíbia ou fíbula canina, preservado com mel, associado a fios de aço Inter fragmentar no tratamento de fratura diafisária umeral foi eficiente (Figura 10). Tal fator pode ser referente a capacidade do mel em reduzir a antigenicidade do xenoenxerto ósseo cortical.

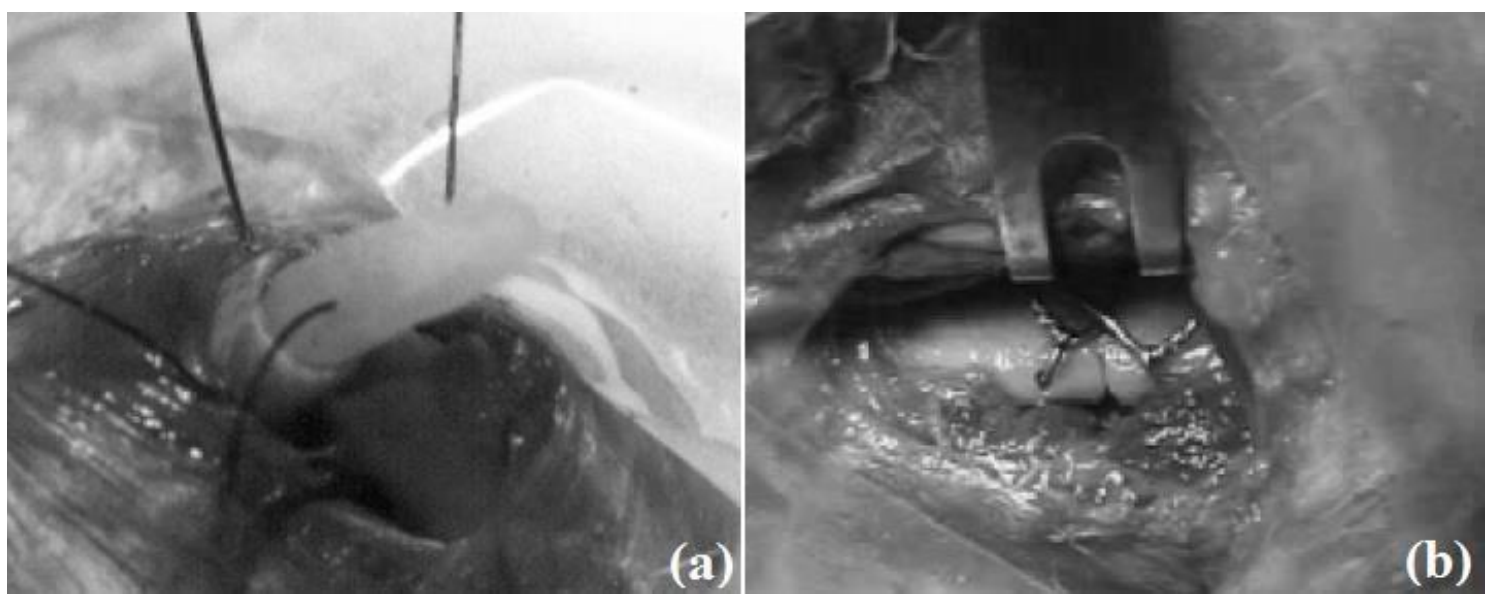

Figura 10. Osteossíntese de úmero por xenoenxerto ósseo em Columbia livia. (A) Inserção do xenoenxerto a porção proximal. (B) Redução da fratura e fechamento dos nós dos fios de aço, configurando hemicerclagem em oito. Fonte: Gaiga \& Schossler (2003).

Bolson et al. (2005) realizaram trabalho onde se testou a eficácia da utilização de implante de poliuretano derivado de polímero de mamona (Ricinnus communis) em fratura umeral de codornas domésticas (Coturnix japonica) e obtiveram resultados satisfatórios, encontrando na mamona um material biocompatível com aves, por apresentar osteointegração. Coles (2007) relatou que fraturas de rádio ulna ocorrem geralmente em apenas um dos ossos e o mais sensato nesses casos é não adotar nenhuma medida, pois o osso não fraturado irá auxiliar na aposição normal do osso fraturado, necessitando apenas de imobilização externa, medida apoiada por Ritchie et al. (1997). Dentre os dois ossos, a ulna sofre maior estresse durante o movimento, logo, em fraturas onde ambos os ossos são comprometidos, opta-se por realizar tratamento na ulna (Ferrigno et al., 2014); porém, Helmer \& Redig (2006) afirmaram que a fixação do rádio é obrigatória, enquanto da ulna é recomendada, mas opcional. Tratamento por fixação externa e uso de pino utilizando fios de Kirschner também são recomendados (Coles, 2007). Os fixadores externos são recomendados para fraturas de rádio-ulna tanto proximais quanto distais, em todos os portes, por apresentar maior estabilidade, melhor aposição dos fragmentos e ser menos invasiva, possibilitando boa manutenção da vascularização. As fraturas muito proximais devem ser tratadas com fixadores trans articulares, porém não apresenta bom prognóstico para o voo (Helmer \& Redig, 2006). Ritchie et al. (1997) consideraram o uso de placas ósseas uma opção em fraturas de ulna.

Quanto aos membros pélvicos, Dalmolin et al. (2007) relataram que as fraturas desses membros ocorrem com maior frequência em aves terrestres e que vivem em gaiolas, com maior comprometimento de epífise distal e diáfise pela pouca cobertura muscular. $\mathrm{O}$ uso de pinos intramedulares possui pouca utilidade na cooptação dos fragmentos ósseos, pois estes sofrem muito pelas forças de compressão (Ferrigno et al., 2014). A abordagem cirúrgica do fêmur é feita lateralmente (Coles, 2007; Ferrigno et al., 2014; Helmer \& Redig, 2006; Ritchie et al., 1997). De acordo com Ferrigno et al. (2014), em fraturas proximais e distais, utiliza-se a técnica de pinos cruzados, enquanto para Helmer \& Redig (2006), as fraturas proximais são melhor tratadas com utilização de aparelhos de banda de tensão e fraturas distais por colocação de pinos cruzados. A utilização de pinos intramedulares é recomendada por Ritchie et al. (1997) em fraturas proximais e metafisárias de fêmur, com sucesso.

Segundo Ritchie et al. (1997) para fraturas transversas diafisárias, em aves de pequeno e médio porte, utiliza-se pino intramedular, inserido de maneira retrógrada e, estudos de Helmer \& Redig (2006) mostraram que fraturas diafisárias são melhor tratadas com uso de fixadores híbridos, porém pinos intramedulares isolados podem ser utilizados em aves de pequeno porte. No caso de fraturas complexas, como uma cominutiva, recomenda-se o uso de fixador externo, com no mínimo dois pinos em cada fragmento ósseo. O pino proximal deve estar distal ao acetábulo e o distal entre os côndilos. A combinação de pino intramedular e fixação externa confere $30 \%$ de rigidez ao aparelho. O uso de placas 
ósseas em fraturas de fêmur em aves de grande porte é recomendado (Ferrigno et al., 2014). De acordo com Westfall \& Egger (1979), fraturas de membros pélvicos são mais adaptáveis ao uso de placas e parafusos ósseos, pois os ossos não se quebram tão facilmente, pelo córtex mais espesso, promovendo assim maior estabilidade.

Estudo de Santana et al. (2014), em coruja buraqueira (Athene cunicularia), utilizando fixador externo linear tipo I em fratura oblíqua de fêmur, onde se utilizaram agulhas $25 \times 0,7 \mathrm{~mm}$ como pinos, fixados a capa de agulha $40 \times 1,2 \mathrm{~mm}$ preenchida com metilmetacrilato, mostrou retorno precoce do membro.

Fraturas de tibiotarso possuem abordagem medial de acordo com Ferrigno et al. (2014), e crâniomedial segundo Ritchie et al. (1997) e Coles (2007). São muito comuns em aves domésticas (fratura medial-distal) e em aves de falcoaria (fratura proximal) (Helmer \& Redig, 2006). Em fraturas transversais de aves de pequeno e médio porte, recomenda-se o uso de pino intramedular, como relatado por Lima et al. (2013), em fratura medial de tibiotarso esquerdo de periquito australiano (Melopsittacus undulatus), onde o animal foi submetido a colocação de agulhas hipodérmicas atuando como pino intramedular, permitindo adequada justaposição dos componentes ósseos e sustentação do membro afetado.

Já em casos de aves de médio e grande porte, utilizam-se fixadores externos bipolares, com no mínimo dois pinos em cada fragmento. Também pode associar pino intramedular e fixação externa, com o cuidado de manter o diâmetro do pino inferior a 30\% do diâmetro do canal medular (Ferrigno et al., 2014).

Alievi et al. (2001), em pombos domésticos (Columbia livia) e Conti et al. (2007), em galinhas da raça Plymouth Rock Branca utilizaram fixador externo tipo II, com pinos colocados em angulação de $70^{\circ}$, fixados as barras de acrílico autopolimerizável, uma na face medial e outra na face lateral do membro. Em ambos experimentos, foi constatada a eficiência do método (Figura 11).

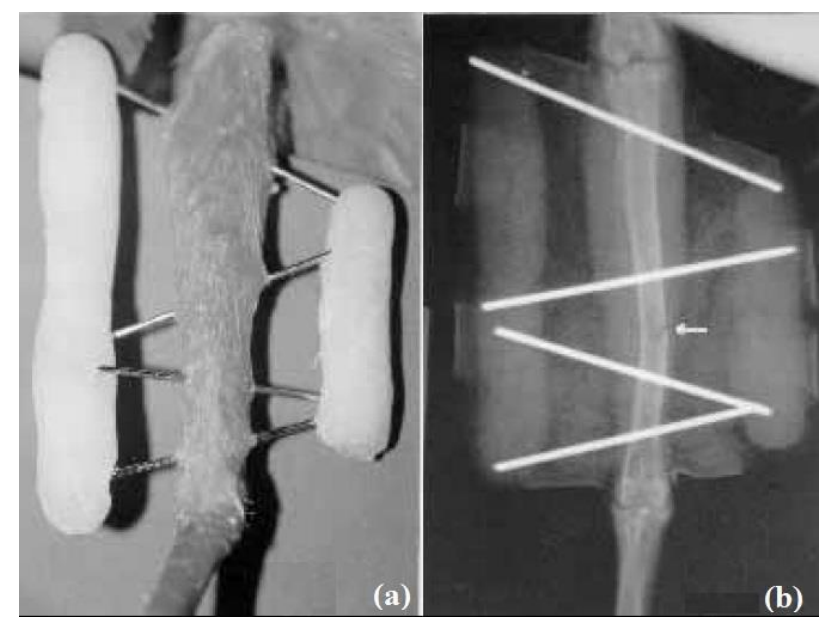

Figura 11. Redução fechada e fixação esquelética externa tipo II em Columbia livia. (A) Tibiotarso direito após inserção dos pinos e barra de acrílico autopolimerizável. (B) Radiografia do pós-operatório imediato, com presença de linha de fratura (seta). Fonte: Alievi et al. (2001).

Arias et al. (2015) relataram o uso de massa epóxi como alternativa viável ao PMMA em fratura de periquito choroy selvagem (Enichognatus leptorhynchus), por atingir menores temperaturas de polimerização, diminuindo assim o risco de necrose óssea. Dal-Bó et al. (2012) utilizaram fixação externa trans articular tipo II em fratura completa oblíqua com esquírola na diáfise distal de tibiotarso de gavião carrapateiro (Milvago chimachima), com colocação de três pinos no fragmento proximal e 1 no distal, além de 2 no tarsometatarso, fixados a barras acrílicas autopolimerizáveis. O animal apresentou recuperação tardia, devido, provavelmente, ao dano causado aos nervos tibial e fibular durante a fratura. Apesar disso, o animal conseguiu recuperar plena funcionalidade do membro.

Coles (2007) recomendou o uso de fixador híbrido em fraturas transversais de tibiotarso, evitando assim a rotação do fragmento distal. Harcourt \& Brown (1996, apud Coles, 2007) sugeriram o uso de uma técnica onde 2 fios de Kirschner são passados cruzados pelas laterais dos epicôndilos tibiotarsais, 
entrando na cavidade medular e aproximando os fragmentos de fratura. As extremidades distais são então enganchadas nos epicôndilos. Redig (2000 apud Coles, 2007) sugeriu o uso de uma técnica do tipo "tie in", em que se insere uma canaleta de polipropileno no canal medular para coaptar os fragmentos da diáfise, seguido da inserção de pinos transversais, paralelos ao eixo do osso. Helmer \& Redig (2006) recomendaram a associação de pinos intramedulares ou fios de Kirschner com imobilização externa em aves de pequeno porte, considerando agulhas hipodérmicas como uma alternativa aos pinos intramedulares.

Sá et al. (2012) utilizaram miniplaca, parafusos e fios de cerclagem em fratura simples e espiral no terço medial de tíbia de ganso (Anser anser). $\mathrm{O}$ autor relatou consolidação óssea por primeira intenção e sucesso de retorno à função do membro (Figura 12).

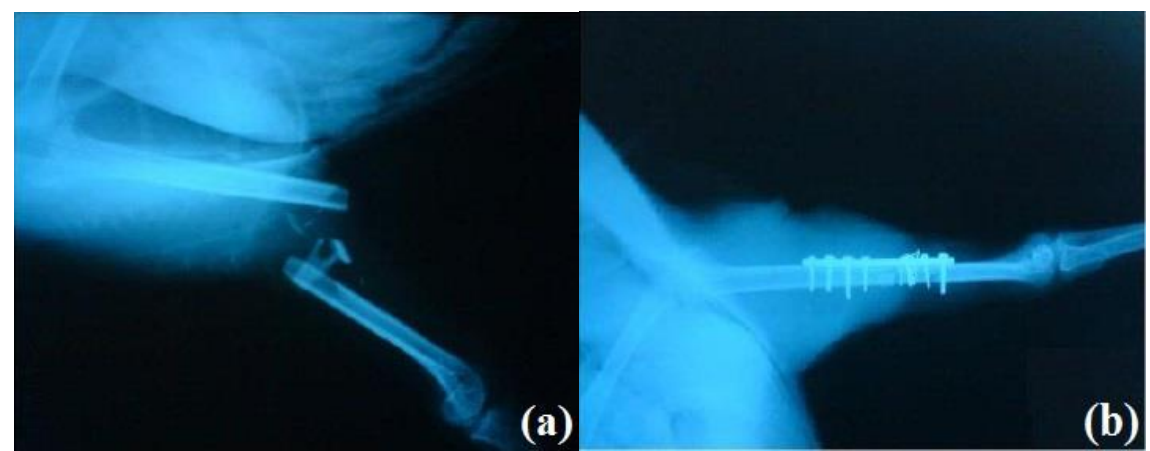

Figura 12. Imagens radiográficas de tíbia de Anser anser. (A) Radiografia de fratura em terço médio de tíbia com presença de esquírolas. (B) Radiografia pós-operatória com uso de miniplaca, parafusos e fios de cerclagem. Fonte: $\underline{\text { Sá et al. (2012). }}$.

Dal-Bó et al. (2011) também optaram pelo uso de miniplaca, em fratura completa transversa em terço proximal de diáfise tibiotarsal de arara canindé (Ara ararauna) (Figura 13). Aos 30 dias, a fratura encontravase consolidada e alinhada, sem calo ósseo exuberante e afrouxamento dos implantes, optando-se pela não retirada do implante, mostrando-se mais uma alternativa ao uso em fraturas de aves de vida livre.

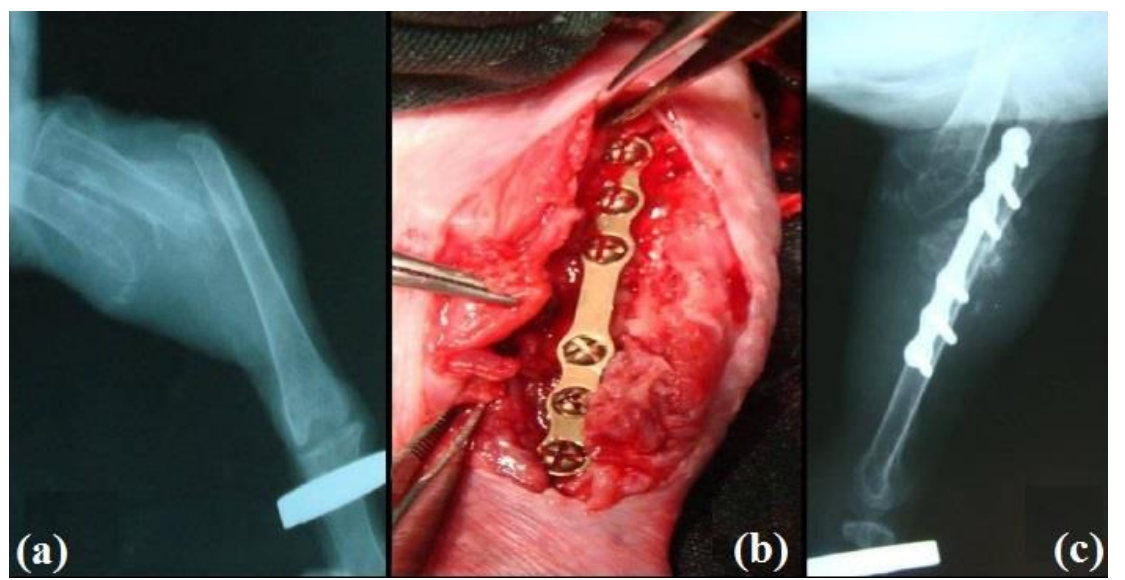

Figura 13. Osteossíntese de tibiotarso com miniplaca de titânio em Ara ararauna. (A) Radiografia de fratura completa transversa em diáfise e reação periosteal, (B) Fratura reduzida com colocação de miniplaca de titânio, (C) Radiografia pósoperatória evidenciando alinhamento da fratura. Fonte: Dal-Bó et al. (2011).

Gouvêa et al. (2011) realizaram estudo onde foram utilizados 3 tamanhos de miniplacas de titânio em fratura de médio-diafisária transversa de tibiotarso, onde observou-se que as placas menores obtiveram maiores complicações (envergamento da placa, desvio angular do membro e retorno tardio da função), sendo de uso desaconselhado, enquanto que as placas maiores apresentaram resultado mais satisfatório. Em fraturas de tarsometatarso, a abordagem é medial e geralmente tratada com uso de fixadores externos (Ferrigno et al., 2014), não sendo recomendado o uso de pinos intramedulares pelo risco de dano aos tendões flexores presentes (Helmer \& Redig, 2006). 
Torres et al. (2007) utilizaram a fixação externa em fratura exposta simples completa transversa em terço distal de tarsometatarso de membro posterior direito de seriema (Cariama cristata), onde o membro apresentava também desvio de eixo. Foram inseridos 4 pinos de Steimann 2mm, sendo que os dois mais distais ao foco de fratura foram introduzidos perpendicular ao eixo ósseo e os proximais em ângulo de aproximadamente $70^{\circ}$, todos fixados em barra de acrílico preenchida com PMMA (Figura 14). Foi observado, aos 45 dias pós-operatórios, formação do calo ósseo exuberante e lise no trajeto dos pinos, complicação comum que leva ao afrouxamento do dispositivo. Apesar disso, a técnica se mostrou eficiente, com retorno de função do membro.

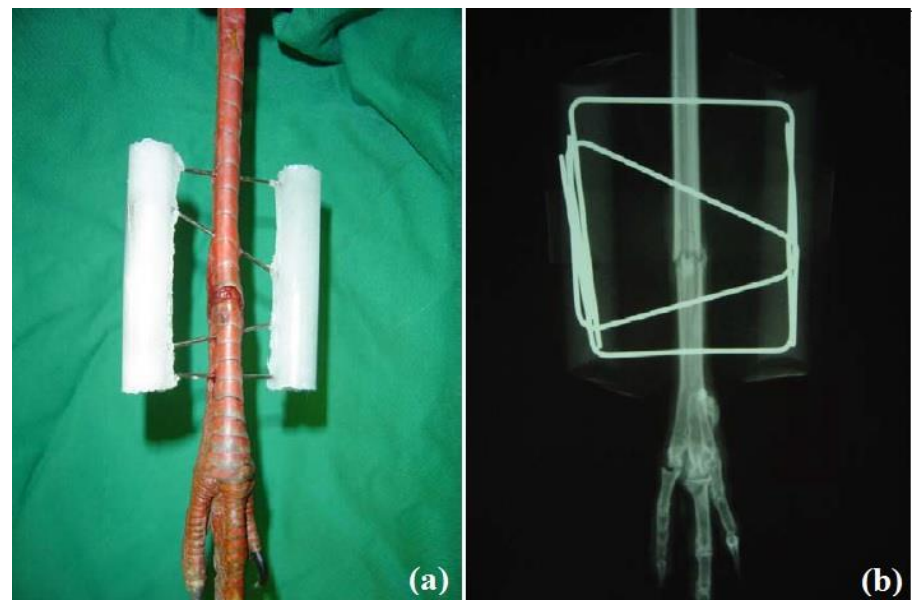

Figura 14. Fixação esquelética externa em fratura tarsometatársica de Cariama cristata. (A) Redução fechada com fixador externo tipo II, utilizando pinos e barras de acrílico preenchidas com PMMA, (B) Radiografia do pós-operatório imediato, evidenciando a angulação dos pinos, com presença da linha de fratura. Fonte: Torres et al. (2007).

\section{Conclusão}

Afecções traumáticas em aves, com destaque para fraturas, tem se tornado cada vez mais comuns na rotina do médico veterinário e necessitam de adequada intervenção terapêutica. Porém, poucos são os profissionais que se arriscam a realizar tais procedimentos, pela existência de características físicas e fisiológicas distintas dessa classe, carecendo de grande conhecimento anatômico e princípios básicos de cirurgia ortopédica geral. A escolha da técnica cirúrgica deve considerar as necessidades das diferentes espécies, tamanhos e pesos, onde cada técnica será melhor aplicada para cada caso. Assim, a cirurgia ortopédica em aves constitui um campo em ascensão, vasto para pesquisas e experimentações, visando à saúde e o bem-estar desses animais.

\section{Referências bibliográficas}

Alievi, M. M., Oliveira, A. N. C., Ferreira, P. A., Traesel, C., Guimarães, L. D., Flores, F., Silva, S. F., \& Schossler, J. E. W. (2008). Osteossíntese de úmero em pombos domésticos (Columba livia) associando-se pinos metálicos e polimetilmetacrilato intramedulares após osteotomia diafisária. Arquivo Brasileiro de Medicina Veterinária e Zootecnia, 60(4), 843-850. DOI: https://doi.org/10.1590/S0102-09352008000400011

Alievi, M. M., Schossler, J. E., Hippler, R. A., Alves, A. S., Pellegrini, L. C., \& Langohr, I. M. (2001). Redução fechada e fixação esquelética externa tipo II para o tratamento de fraturas de tibiotarso em pombos domésticos (Columba livia). Ciência Rural, 31(6), 1019-1025. DOI: https://doi.org/10.1590/s0103-84782001000600017

Arias, J. I., Beato, C., \& Espinoza, A. (2015). Fixação externa com massa epóxi em uma fratura tibiotársica de um periquito choroy selvage (Enicognathus leptorhynchus). Arquivo Brasileiro de Medicina Veterinária e Zootecnia, 67(3), 671-678. DOI: https://doi.org/10.1590/1678-4162-7474

Bennett, R. A., \& Kuzma, A. B. (1992). Fracture management in birds. Journal of Zoo and Wildlife Medicine, 23, 5-38.

Bolson, J., Schossler, J. E., Ornes, R. C., Mottin, V., \& Alberti, T. (2005). Análise clínica, radiológica, 
macroscópica e histológica do úmero de codornas domésticas (Coturnix japonica), submetido ao implante da poliuretana derivada do polímero de mamona (Ricinnus communis). Ciência Rural, 35(5), 1123-1130. DOI: https://doi.org/10.1590/s0103-84782005000500021

Bolson, J., \& Schossler, J. E. W. (2008). Osteossíntese em aves-revisão da literatura. Arquivos de Ciências Veterinárias e Zoologia Da UNIPAR, 11(1), 55-62.

Brinker, W. O., Piermattei, D. L., \& Flo, G. L. (1986). Manual de ortepedia e tratamento das fraturas dos pequenos animais. Manole São Paulo.

Bush, R. M. (1974). External fixation of avian fractures. Journal of the American Veterinary Medical Association, 3(1), 64-65. DOI: https://doi.org/10.1111/j.1532-950X.1974.tb01543.x

Coles, B. (2007). Essential of avian medicince and surgery. Blackwell Publishers Inc.

Conti, J. B., Schossler, J. E. W., Alievi, M. M., Bonfada, A. T., Novosad, D., Silva, D., \& Pachaly, J. R. (2007). Uso do fixador esquelético externo Tipo II para osteossíntese de tibiotarso em galinhas da raça Plymouth $\mathrm{R}$ de tibiotarso em galinhas da raça Plymouth Rock Branca: ock Branca: modelo experimental para uso em aves selvagens1. Pesquisa Veterinária Brasileira, 27(5), 199-204. DOI: https://doi.org/10.1590/s0100-736x2007000500003

Cubas, Z. S., Silva, J. C. R., \& Dias, J. L. C. (2014). Tratado de animais selvagens-medicina veterinária. Editora Roca.

Cunha, O. da, Rios, A., Taffarel, M. O., Fernandes, D. R., Cavalcante, C. Z., Camargo, G. V. H. de, Victor, K. M., Sovinski, Â. I., \& Giordano, T. (2004). Osteossíntese de úmero com êmbolo de seringa em pombos domésticos. Revista Científica de Medicina e Veterinária, 2(6), 87-90.

Dal-Bó, I. S., Alievi, M. M., Silva, L. M., Gouvea, A. S., Mucillo, M. S., Santos, E. O., \& Beck, C. A. C. (2011). Osteossíntese de tibiotarso com miniplaca de titânio em arara canindé (Ara ararauna). Arquivo Brasileiro de Medicina Veterinária e Zootecnia, 63(4), 1003-1006. DOI: https://doi.org/10.1590/S0102-09352011000400028

Dal-Bó, Í. S., Chagas, J. A. B., Oliveira, R. P., Ferreira, M. P., Nóbrega, Fernanda SilveiraQuadros, A. M., Spasin, J. E., \& Brun, M. V. (2012). Osteossíntese de tibiotarso com fixador esquelético externo transarticular tipo II em gavião carrapateiro (Milvago chimachima)-relato de caso. Revista Científica de Medicina Veterinária - Pequenos Animais e Animais de Estimação, 10(32), 56-60.

Dalmolin, F., Schossler, J. E., Bertoletti, B., Vasconcelos, A., Muller, D., Schossler, D. R., \& Gomes, K. (2007). Modificações do fixador externo para osteossíntese umeral em pombos domésticos. Ciência Rural, 37(2), 443-449. DOI: https://doi.org/10.1590/s0103-84782007000200023

Denny, H. R., \& Butterworth, S. J. (2000). A guide to canine and feline orthopaedic surgery. Blackwell Science.

Dunning, D., Halling, K. B., \& Ehrhart, N. (2005). Rehabilitation of medical and acute care patients. Veterinary Clinics: Small Animal Practice, 35(6), 1411-1426. DOI: https://doi.org/10.1016/j.cvsm.2005.08.008

Dyce, K. M., Wensing, C. J. G., \& Sack, W. O. (2004). Tratado de anatomia veterinária. Elsevier Brasil.

Ferrigno, C. R. A.; Schmaedecke, A.; Ferraz, V. (2014). Ortopedia. In: Cubas, Z. S.; Silva, J. C. R.; Catão-Dias, J. L. Tratado de Animais Selvagens: Medicina Veterinária. (v2.) São Paulo: Roca,. p. 2304-2323.

Fossum, T. W. (2014). Cirurgia de pequenos animais (4th ed., Vol. 1). Elsevier Brasil.

Gaiga, L. H., \& Schossler, J. E. W. (2003). Osteossíntese de úmero por xenoenxerto ósseo preservado em mel em pombos domésticos (Columba livia). Ciência Rural, 33(4), 709-715. DOI: https://doi.org/10.1590/s0103-84782003000400020

Gondim, L. S. Q., Gomes, D. M., \& Maia, P. C. C. (2006). Casuística de aves selvagens atendidas de 2002 a 2004 na Escola de Medicina Veterinária da Universidade Federal da Bahia. Congresso Brasileeiro de Zoologia, 26, 86-87.

Gouvêa, A. S., Alievi, M. M., Noriega, V., Dal-Bó, Í. dos S., Pinto, T. M., Menezes, C. L. M. de, Silva, R. B., Silva, L. M. da, Velasque, A. G., \& Pinto, L. A. T. (2011). Microplacas de titânio em fraturas de tibiotarso em pombos domésticos. Ciência Rural, 41(3), 476-482. DOI: https://doi.org/10.1590/S0103-84782011000300018 
Helmer, P., \& Redig, P. T. (2006). Surgical resolution of orthopedic disorders. Clinical Avian Medicine, 2, 761-774.

Junqueira, L. C., \& Carneiro, J. C. (2013). Histologia Básica (12 ed.). Guanabara Koogan.

Leotte, A. M., Raiser, A. G., Braga, F. A., Krauspenhar, L., Camargo, S. F., Flores, F. N., Gomes, K., \& Scherer, R. S. (2004). Fixação esquelética externa tipo Ia (unilateral-uniplanar) para osteossíntese diafisária de úmero em pombos domésticos (Columba livia). Ciência Rural, 34(6), 1865-1870. DOI: https://doi.org/10.1590/s0103-84782004000600030

Lima, D. B. C., Rodrigues, M. C., Lima, D., Lima, W. C., Quessada, A. M., \& Silva, L. S. (2014). Técnica de Doyle na correção de fratura completa em úmero de tucano (Ramphastos toco): relato de caso. Arquivo Brasileiro de Medicina Veterinária e Zootecnia, 66(6), 1676-1680. DOI: https://doi.org/10.1590/1678-6964

Lima, D. B. C., Rodrigues, M. C., Lima, D. A., Rizzo, M. S., Quessada, A. M., \& Lima, W. C. (2013). Correção cirúrgica de fratura no tibiotarso de periquito-australiano (Melopsittacus undulatus) relato de caso. Clínica Veterinária, 18(10), 46-50.

Macwhirter, P. (2009). Basic anatomy, physiology and nutrition. In T. N. Tully, G. M. Dorresteir, \& A. K. Jones (Eds.), Handbook of Avian Medicine (pp. 1-25). Elselvier Saunders. DOI: https://doi.org/10.1016/b978-0-7020-2874-8.00002-x

Ritchie, B. W., Hsarrison, G. J., Zantop, D., \& Harrison R, L. (1997). Avian medicine: principles and application, abridged edition. Idaho Falls, ID: Wingers Publishing.

Rocha, L. B. (2011). Osteossíntese em fratura de epífise distal de úmero em papagaio verdadeiro (Amazona aestiva). Medicina Veterinária, 3(3), 26-30.

Sá, S. S., Silva Filho, J. C., Souza, F. L., Franco, R. P., Scorsato, P. S., \& Repetti, C. S. F. (2012). Osteossíntese tibial com utilização de mini placa, parafusos e fio de cerclagem em ganso (Anser anser): Relato de caso. Acta Veterinaria Brasilica, 6(1), 61-64.

Samuelson, P. (2011). Tratado de histologia veterinária. Elsevier Health Sciences.

Santana, N.G., Martins, M.G., Miranda, W.M., Araújo, M.C.R., \& Tossini, I.E.S. (2014). Osteossíntese femoral em coruja buraqueira (Atheme cunicularia) com fixador externo linear: relato de caso. Anais do $33^{\circ}$ ANCLIVEPA, Belém, 962-964.

Santos, G. G. C., Matuella, G. A., Coraiola, A. M., Silva, L. C. S., Lange, R. R., \& Santin, E. (2008). Doenças de aves selvagens diagnosticadas na Universidade Federal do Paraná (2003-2007). Pesquisa Veterinária Brasileira, 28(11), 565-570. DOI: https://doi.org/10.1590/s0100-736x2008001100005

Slatter, D. H. (1998). Manual de cirurgia de pequenos animais (Vol. 2). Manole São Paulo.

Souza, L. A., Eurides, D., Dias, T. A., Oliveira, B. J. N. A., Silva, L. A. F., Mota, F. C. D., \& Carneiro, J. S. (2010). Redução de fraturas ósseas em aves: Revisão de literatura. PUBVET, 4(1), Art-710.

Torres, B. B. J., Muzzi, L. A. L., Alves, E. G. L., Leite, C. A. L., Feliciano, M. A. R., Sampaio, G. R., \& Muzzi, R. A. L. (2007). Fixação esquelética externa em fratura tarsometatársica de seriema (Cariama cristata): relato de caso. Arquivo Brasileiro de Medicina Veterinária e Zootecnia, 59(1), 155-159. DOI: https://doi.org/10.1590/s0102-09352007000100026

Tranquilim, M. V., Botelho, G. G. K., Bertolini, Z., Lehmkuhl, R. C., \& Lange, R. R. (2007). Osteossíntese de úmero em Ramphastos dicolorus (tucano de bico verde): relato de caso Osteosynthesis of humerus fracture in Ramphastos dicolorus (redbreasted toucan): case report. Ambiência, 3(2), 261-266.

Westfall, M. L., \& Egger, E. L. (1979). The management of long bone fractures in birds. Iowa State University Veterinarian, 4l(2), 7.

Recebido: 3 de junho, 2020.

Aprovado: 8 de julho, 2020.

Disponível online: 19 de agosto, 2020.

Licenciamento: Este artigo é publicado na modalidade Acesso Aberto sob a licença Creative Commons Atribuição 4.0 (CC-BY 4.0), a qual permite uso irrestrito, distribuição, reprodução em qualquer meio, desde que o autor e a fonte sejam devidamente creditados. 